British Journal of Nutrition (2022), 128, 2063-2074

doi:10.1017/S0007114521004712

(C) The Author(s), 2021. Published by Cambridge University Press on behalf of The Nutrition Society. This is an Open Access article, distributed under the terms of the Creative Commons Attribution licence (https://creativecommons.org/licenses/by/4.0/), which permits unrestricted re-use, distribution, and reproduction in any medium, provided the original work is properly cited.

\title{
Examination of dietary intake of UK preschool children by varying carers: evidence from the 2008-2016 UK National Diet and Nutrition Survey
}

\author{
Colette Marr ${ }^{1 *}$, Penny Breeze ${ }^{2}$ and Samantha J. Caton ${ }^{1 *}$ \\ ${ }^{1}$ Public Health, School of Health and Related Research (ScHARR), University of Sheffield, Sheffield, UK \\ ${ }^{2}$ Health Economics and Decision Science, School of Health and Related Research (ScHARR), University of Sheffield, Sheffield, UK
}

(Submitted 14 December 2020 - Final revision received 8 November 2021 - Accepted 25 November 2021 - First published online 29 November 2021)

\section{Abstract}

Early years caregivers can play a key role in young children's eating and the prevention of childhood obesity. The UK National Diet and Nutrition Survey (NDNS) is a large representative survey collecting detailed food and nutrition consumption data. Using these data, the aim of this study was to investigate the relationship between dietary intake of preschool children in the UK aged 2 to 4 years and accompanying adult/s. Nutrition consumption data from 1218 preschool children from years 1 to 8 of the 2008-2016 NDNS were accessed. Dietary data were captured using 3 or 4 day estimated food diaries. Regression analyses revealed significant differences in consumption when children were not accompanied by their parents. Compared with when children were with parents, children consumed significantly more energy dense meals (0.32 kJ/g, $95 \% \mathrm{CI}$ $0 \cdot 1-0 \cdot 6 \mathrm{~kJ} / \mathrm{g})$, energy $(62 \mathrm{~kJ} / \mathrm{g},(95 \% \mathrm{CI} 27-97 \mathrm{~kJ})) \mathrm{Na}(19 \mathrm{mg},(95 \% \mathrm{CI} 6,32))$, added sugars $(0 \cdot 6 \mathrm{~g},(95 \% \mathrm{CI} 0 \cdot 1,1 \cdot 1))$, vegetables (3 g, (95 \% CI 1 , 4)), total grams (12 g, (95\% CI 3, 21)) and saturated fat $(0 \cdot 2 \mathrm{~g},(95 \% \mathrm{CI} 0 \cdot 1,0 \cdot 4))$ per eating occasion when accompanied by wider family. When children were accompanied by a formal childcare provider, they consumed significantly lower energy dense meals $(-0.9 \mathrm{~kJ} / \mathrm{g},(95 \% \mathrm{CI}-1 \cdot 4-$ $-0.3 \mathrm{~kJ} / \mathrm{g}))$, less added sugars $(-1.6 \mathrm{~g},(95 \% \mathrm{CI}-2 \cdot 4,-0 \cdot 8))$ and more fruit $(12 \mathrm{~g},(95 \% \mathrm{CI} 3,21))$ per eating occasion than when they were with their parents. The results demonstrate that non-parental caregivers might be an important target to promote healthy eating in young children. Further research is needed to establish which caregivers would benefit most.

Key words: Preschool children: Dietary intake: Caregivers: NDNS: Childhood obesity

Globally, in 2019, 38 million children under the age of 5 years were overweight or obese $\mathrm{e}^{(1)}$, and poor dietary choices are partly responsible for this. Although the first few years of a child's life are documented as a critical period for the development of healthy eating habits, in the UK, preschool children are consuming over double the recommended amount of free sugars per day and exceeding their recommended intake of saturated fat ${ }^{(2)}$. Many children in England are also failing to meet the recommended daily intake of fruit and vegetables ${ }^{(3)}$. Caregivers (e.g. parents, family, childminders and nursery staff) of young children are nutritional gatekeepers, selecting the types and amount of food and drinks they receive ${ }^{(4)}$. There are a wealth of publications exploring parental feeding ${ }^{(5-8)}$, but few have investigated the influence of other caregivers, such as other family members, nursery staff and childminders, on young children's eating. This may be a key oversight in exploring the factors associated with early childhood obesity.

Over the last 20 years, the employment rate of mothers has grown substantially and $73 \%$ of couple families have both parents in employment in the $\mathrm{UK}^{(9)}$. Consequently, parents rely on both formal and informal caregivers for childcare. Formal childcare is government-regulated and can be provided free as part of the entitlement to early years provision or paid for directly by parents. Formal childcare includes nurseries and registered childminders. Informal childcare is the converse of formal childcare, often provided by family and friends. Children aged 3 to 4 years in the UK are entitled to $30 \mathrm{~h}$ of free childcare per week with a formal childcare provider; however, for children younger than this, there is limited free provision and therefore informal childcare is often used. In a recent survey of English parents of children aged 0-14 years, $62 \%$ had used formal childcare and $35 \%$ of families had used informal childcare provided by family and friends. More specifically, $40 \%$ of preschool children up to the age of 2 years and $88 \%$ of children aged 3 to 4 years had received formal childcare. The data are not so clear with regard to informal childcare, since it is likely to be used outside of traditional working hours and school holidays $^{(10)}$. For children below school age, this often involves a full

Abbreviation: NDNS, National Diet and Nutrition Survey

* Corresponding authors: C. Marr, email c.kearney@sheffield.ac.uk; Dr S. J. Caton, email s.caton@sheffield.ac.uk 
day of childcare involving multiple meals and snacks, and therefore the influence these caregivers are having on young children's diets requires more exploration.

Research into the provision of food and drink in formal childcare settings focuses mainly on nurseries. In the past, there is evidence to suggest that nurseries were failing to develop healthy eating habits in young children, providing meals deficient in energy, carbohydrate, $\mathrm{Fe}$ and $\mathrm{Zn}$ and exceeding the recommended Na guidelines ${ }^{(11)}$. In another study, many nurseries were not providing a single portion of fruit or vegetables with the children's main meal ${ }^{(12)}$. However, since the voluntary food and drink guidelines for early years settings were released in 2012, nurseries started to serve food and beverages more consistent with the guidelines ${ }^{(13)}$. Although these studies go some way in demonstrating the dietary quality in nursery settings, there is still a lack of up-to-date data on food provision in UK nurseries. Research into the food provision in childminder settings is scarce; however, a qualitative study of eight childminders found that although childminders were aware of key nutritional campaigns such as the 'five a day', there was an over-reliance on the provision of fresh and dried fruit as snacks and no consistency in providing vegetables with meals ${ }^{(14)}$. Most of the childminders were also unaware of the voluntary food and drink guidelines for early years settings ${ }^{(14)}$.

There is also a distinct paucity of evidence examining food provision by informal childcare providers such as family members. Instead, research has focused on weight outcomes of children in formal $v$. informal childcare, with mixed findings. For instance, in the UK-wide cohort study, 12354 3-year-olds children who were cared for in informal childcare settings were significantly more likely to be overweight than those cared for by their parents, whereas no significant relationship existed for those in formal childcare ${ }^{(15)}$. Although there is little evidence for the association between childcare type and weight status persisting beyond the early years ${ }^{(16,17)}$, it suggests that exploring the food provision by family members who are not parents may be important.

The National Diet and Nutrition Survey (NDNS) ${ }^{(18)}$ is a representative survey collecting detailed food consumption and nutrient intake data of individuals aged one and a half years and over, from the UK. For children, parents are asked to complete food diaries, regarded as the gold standard in dietary assessment methods ${ }^{(19)}$, for all food and drinks consumed over 3 d. Parents also document who the child is with when they consume these foods. Consequently the NDNS may be an invaluable resource that can be utilised to explore the dietary provision of formal and informal caregivers.

A previous study has explored the relationship between children's fruit and vegetable intake and the eating context, including who the child was with, using data from the $\mathrm{NDNS}^{(20)}$. Children aged one and a half to 3 years were more likely to consume vegetables when siblings were present, when they were with adult relatives and when with formal childcare providers, such as nursery/kindergarten staff and childminders, compared with when they were with their parents alone. Children were less likely to consume vegetables when alone, and they were also more likely to consume fruit when they were with their formal childcare provider and when they were with friends. Although this study highlights the difference in fruit and vegetable intake when children are with different adult figures, it does not provide insight into young children's overall diet provision when accompanied by different people. Doing so would provide a greater insight into ways to improve children's diets.

There is also a need to consider socio-economic factors when exploring children's dietary intake when with different caregivers ${ }^{(21)}$. Socio-economic gradients in diets have been documented widely for both adults and children, with lowerincome groups consuming lower-quality diets than higherincome groups ${ }^{(22-25)}$, and this is primarily due to reduced access and a higher cost of more healthful diets ${ }^{(23)}$. Less is known about how the child's parental household income, a proxy measure of socio-economic status, might influence young children's dietary intake within a caregiving environment.

The aim of this study is to investigate the relationship between dietary intake (energy $(\mathrm{kJ})$, total added sugars $(\mathrm{g})$, total $\mathrm{Na}(\mathrm{mg})$, energy density $(\mathrm{kJ} / \mathrm{g})$, total saturated fat $(\mathrm{g})$, total fruit (g), total vegetables (g) and total grams per eating occasion) of children aged 2 to 4 years in the UK and accompanying adult/s using data from the NDNS. We will also explore the influence of the child's parental household income on children's dietary intake when they are accompanied by different people.

\section{Method}

Research design

This study is a secondary data analysis of quantitative data from a UK national cross-sectional survey.

\section{Data source}

The data were pooled data from the NDNS of years $1-8^{(18)}$. The NDNS is a nationally representative cross-sectional survey assessing the diet and health of households in Great Britain. Data were collected in three waves: wave one: 2008-2011, wave two: 2012-2014 and wave three: 2014-2016. Across the three waves, 39524 households were randomly selected to take part in the study. For each household, either one adult (aged 19 years and over) and one child (aged one and a half to 18 years) or one child only were randomly selected to take part. Participants for the present study were 1218 children aged 2 to 4 years and their caregivers who completed the dietary assessment for the children. The full survey design and sampling methods of the NDNS survey have been published previously ${ }^{(18)}$. Anonymised data were obtained from the UK Data Archive (NatCen, Univeristy of Essex, Colchester, Essex, UK). Ethical approval for the NDNS was obtained from Oxfordshire A Research Ethics Committee.

\section{Dietary data}

Across the three waves, 3 or 4-d estimated food diaries were used to assess dietary intake. Food diaries were completed by parents for children under the age of 12 years, and detailed instructions for caregivers were also provided for when children were not with their parents. To complete the food diaries, caregivers were 
asked to record all food and drink items consumed, both in and out of the home, the time they ate and who they were with. Parents and caregivers were requested to record only the food eaten, taking into consideration any leftovers, and they were provided with picture examples and given detailed instructions on how to estimate portion sizes and were asked to record any weights from labels. Diary entries were coded by trained coders and editors in the NDNS team. For each food item consumed, macro and micronutrients were calculated in a modified version of the Diet in, Nutrients Out system; a dietary recording and analysis system. The food composition data were taken from the Department of Health's NDNS Nutrient databank.

\section{Type of caregiver}

The NDNS coded fifteen categories for who the child was with for each eating occasion and these were recoded into a new variable containing six categories for the current analysis. Three of these categories refer to types of caregivers: 'parents', 'formal childcare providers' and with 'wider family'. The other three categories suggested no obvious caregiver ('no adult specified', 'with others' and 'not recorded') but were retained in the analysis for validity. Any group that included parents was recoded as 'with parents' even if the category also referred to being with a carer, for example, 'with parent/carer \& siblings' as there was no way to distinguish those within it. Exploratory analysis indicated that $94 \%$ of the eating occasions with parents/carer were in the home environment, strengthening the assumption that the carer referred to here is the parent figure. The category 'with family (including relatives)' was recoded as 'with wider family'. One category referred to being with a carer without reference to parents (with carer and other children) and exploratory analysis indicated that $82 \%$ of these eating occasions accompanied by a carer were located at a nursery or kindergarten and $8 \%$ were located at a carer's home indicating that these carers were nursery/kindergarten staff or childminders. Consequently, this category was assumed to be 'formal childcare providers' and will be referred to this as such from this point onwards. When the NDNS categories included no obvious accompanying adult, for example, 'with siblings', 'with friends' these were recoded as 'no adult specified'. Three NDNS categories, referring to with others, were collapsed into a single 'others' category. Finally, the NDNS category 'not specified' whereby participants did not enter into the diary who the child was with when consuming the food was coded as 'not recorded'.

\section{Other variables}

Alongside the food diaries, parents provided demographic information and trained field workers measured the children's body weight and height. BMI was calculated from height and weight, and children were categorised as having a healthy weight, overweight or obesity using the WHO child growth standards ${ }^{(26)}$ for children aged 2 to 3 years, and using the UK90 ${ }^{(27)}$ for children aged 4 years and above. Parents also recorded their child's age in years, their sex, their ethnicity and the household income. For the present study, we extracted the child's parental equivalised household income to use as an indication of socioeconomic status $^{(28)}$, since indices of multiple deprivation scores were not available for all survey waves and nations. Equivalised household income is the total income of a household after tax and other deductions, divided by the number of household members weighted by age. This variable will be referred to as 'household income' throughout.

\section{Data preparation and outcomes}

Food-level dietary data, BMI, equivalised household income, ethnicity, sex and age data were extracted from each wave and combined into one dataset. Energy (kJ), added sugars (g), $\mathrm{Na}(\mathrm{mg})$, saturated fat $(\mathrm{g})$, fruit $(\mathrm{g})$, vegetables $(\mathrm{g})$ and grams from each food or drink item consumed were aggregated based on serial id, exact meal time and the day of the week to create a total for each eating occasion. Energy density per eating occasion was calculated (total kilojoules/total grams).

\section{Statistical analysis}

Means and standard deviations of energy ( $\mathrm{kJ})$, total added sugars (g), total $\mathrm{Na}(\mathrm{mg})$, energy density $(\mathrm{kJ} / \mathrm{g})$, total saturated fat $(\mathrm{g})$, total fruit $(\mathrm{g})$, total vegetables $(\mathrm{g})$ and total grams $(\mathrm{g})$ consumed per eating occasion when children were with the different accompanying adults were calculated to explore any initial associations between intake and accompanying adult. Regression analysis was then used to explore these associations further. Separate models were used to examine the main effect of each level of the 'WhoWith' variable on each of the dietary outcomes (energy (kJ), total added sugars ( $\mathrm{g}$ ), total $\mathrm{Na}(\mathrm{mg})$, energy density $(\mathrm{kJ} / \mathrm{g})$, total saturated fat $(\mathrm{g})$, total fruit $(\mathrm{g})$, total vegetables $(\mathrm{g})$ and total grams/eating occasion). Generalised linear models using clustered robust standard errors were used to control for multiple responses per participant. Sampling weights were applied in accordance with guidance from the NDNS. The models included sex, age, ethnicity (White, Mixed Ethnic group, Black or Black British, Asian or Asian British and any other group), equivalised household income (low $<=£ 17500$, middle $>£ 17500<=£ 32500$ and high $>£ 32$ 500) and child BMI (normal, overweight and obese) to control for these factors which are known to influence dietary intake ${ }^{(22,24,25,29)}$.

Over $10 \%$ of the sample ( $n$ 291) had missing data for child BMI and/or household equivalised income data, which equated to 7769 missing eating occasions. Assuming these data were missing at random, multiple imputations ( $n$ 20) were performed for these two variables using the mi impute function in stata with regress for the continuous household equivalised income variable and mlogit for the categorical BMI variable. All variables used in the planned regression model were included in the imputation model to preserve the relationship between the variables of interest ${ }^{(30)}$. The regression analyses were conducted incorporating the average values from the twenty imputations for those with missing data in accordance with Rubin's rules ${ }^{(31,32)}$.

\section{Sub-group analysis}

We examined the influence of household income on dietary intake ${ }^{(25)}$ and the differences in child intake when accompanied by different people. Although the indices of multiple deprivation score would have been the optimal measure of socio-economic 
status, as it takes into consideration seven different facets of deprivation, indices of multiple deprivation score was not available for all waves and all nations. Consequently household income was used as a proxy for socio-economic status ${ }^{(28)}$. Household income was included in the model as a factor variable in addition to an interaction term between the accompanying person/people and household income categories. This was repeated for each nutritional element (energy $(\mathrm{kJ})$, total added sugars $(\mathrm{g})$, total $\mathrm{Na}(\mathrm{mg})$, energy density $(\mathrm{kJ} / \mathrm{g})$, total saturated fat $(\mathrm{g})$, total fruit $(\mathrm{g})$, total vegetables $(\mathrm{g})$ and total grams (g)).

\section{Sensitivity analysis}

As meal occasions (e.g. breakfast, lunch, evening meal and snack) vary in nutritional composition ${ }^{(33)}$, ideally this should be controlled for in the regression analyses. However, the NDNS dataset does not provide an indication of whether the food eaten is part of breakfast, lunch, the evening meal or a snack, instead, participants record the time that the items were consumed. Although participants' self-identification of meal occasion is frequently used in the literature to define the meal occasion ${ }^{(34-36)}$, where these data are lacking, time has been used as an approximation ${ }^{(37)}$. Consequently, a sensitivity analysis was conducted making assumptions based on the time items were consumed to control for meal type in the regression analyses. This assumed that any eating occasion consumed between 6 am and 8.59 am was breakfast, between 12 noon and $1.59 \mathrm{pm}$ was lunch, and between $5 \mathrm{pm}$ and $7.59 \mathrm{pm}$ was the evening meal, and items consumed at all other times were assumed to be snacks.

Data files and documentation for the survey were obtained from the UK Data Archive and analysed using Stata version 16.1.

\section{Results}

\section{Child characteristics}

Data from 1218 children were included in the analysis, and Table 1 presents the child characteristics. There were similar percentages of males and females in the sample and similar percentages of children aged 2 or 3 years; however, there were slightly less 4-year-olds (29\%). Although a similar number of children were from low- and high-income families $(31 \%$ and $32 \%$, respectively), there were slightly more from middleincome families (38\%). A greater proportion of the sample were White British and of normal BMI, but the distributions of ethnicity and BMI closely reflect national statistics.

\section{Descriptive statistics of eating occasions}

Across the 1218 children, 30652 eating occasions were included in the analysis. The child had most of the eating occasions accompanied by parents (47\%) followed by occasions when no adult was recorded as present (18\%) and when accompanied by wider family members (17\%). The fewest meal occasions were accompanied by a formal childcare provider $(2 \%)$ or others (3\%). In $13 \%$ of the eating occasions, the accompanying person/ people were not recorded (Table 2).
Table 1. Child characteristics

(Numbers and percentages, $n$ 1218)

\begin{tabular}{lcc}
\hline & $n$ & $\%$ \\
\hline Child sex & & \\
Male & 634 & $52 \%$ \\
Female & 584 & $48 \%$ \\
Child age & & \\
2 & 426 & $36 \%$ \\
3 & 431 & $35 \%$ \\
4 & 351 & $29 \%$ \\
Child ethnicity & & \\
White or White British & 1049 & $86 \%$ \\
Mixed Ethnic group & 41 & $3 \%$ \\
Black or Black British & 27 & $2 \%$ \\
Asian or Asian British & 72 & $2 \%$ \\
Other & 29 & \\
Household Equivlnc & & $31 \%$ \\
Lowest <£17 500 & 375 & $38 \%$ \\
Middle £17 500-£32 499 & 459 & $32 \%$ \\
High >£32 500 & 384 & \\
Child BMl & & $70 \%$ \\
Normal & 847 & $16 \%$ \\
Overweight & 195 & $14 \%$ \\
Obese & 176 & \\
\hline
\end{tabular}

Table 2. No. of eating occasions by accompanying adult

\begin{tabular}{clcc}
\hline & & $\begin{array}{c}\text { No. of eating } \\
\text { occasions }\end{array}$ & $\begin{array}{c}\text { \% of eating } \\
\text { occasions }\end{array}$ \\
\hline $\begin{array}{c}\text { Accompanying } \\
\text { person/people }\end{array}$ & Parents & 14540 & $47 \%$ \\
& Wider family & 5315 & $17 \%$ \\
& $\begin{array}{l}\text { Formal childcare } \\
\text { providers }\end{array}$ & 638 & $2 \%$ \\
& No adult & 5421 & $18 \%$ \\
& specified & & $3 \%$ \\
& Other & 862 & $13 \%$ \\
& Not recorded & 3876 & \\
\hline
\end{tabular}

Table 3 presents the mean dietary intake for each nutritional outcome categorised by who the child was with. Children aged 2 to 4 years consumed the greatest amount of energy (kJ), $\mathrm{Na}(\mathrm{mg})$, total grams and vegetables $(\mathrm{g})$ when accompanied by wider family members. The greatest amount of fruit was consumed when children were accompanied by parents. The most energy-dense meals $(\mathrm{kJ} / \mathrm{g})$ were consumed when children were with others. The greatest amount of saturated fat and added sugars were also consumed when children were accompanied by others. The least amount of energy, saturated fat, $\mathrm{Na}$, vegetables and total grams were consumed when the accompanying people were not recorded by participants. The least amount of added sugars and the lowest energy density meals were consumed when children were accompanied by their formal childcare provider. The least amount of fruit was consumed when children were accompanied by wider family and when the accompanying people were not recorded.

\section{Regression results: nutritional intake when accompanied by different caregivers}

The results from the regression analyses presented in Table 4 (full regression results in appendix 1) indicate that, compared 
Table 3. Mean child nutritional intake at an eating occasion when accompanied by different people

\begin{tabular}{|c|c|c|c|c|c|c|c|c|c|c|c|c|c|}
\hline \multirow{4}{*}{$\begin{array}{l}\text { Outcome } \\
\text { Mean (SD) }\end{array}$} & \multirow[b]{3}{*}{ Energy (kJ) } & \multicolumn{12}{|c|}{ Accompanying person/people(number of eating occasions) } \\
\hline & & \multicolumn{2}{|c|}{$\begin{array}{l}\text { Parents } \\
(14540)\end{array}$} & \multicolumn{2}{|c|}{$\begin{array}{l}\text { Wider family } \\
\quad(5315)\end{array}$} & \multicolumn{2}{|c|}{$\begin{array}{c}\text { Formal } \\
\text { childcare } \\
\text { provider }(638)\end{array}$} & \multicolumn{2}{|c|}{$\begin{array}{c}\text { No adult } \\
\text { specified } \\
(5421)\end{array}$} & \multicolumn{2}{|c|}{ Other (862) } & \multicolumn{2}{|c|}{$\begin{array}{c}\text { Not recorded } \\
\quad(3876)\end{array}$} \\
\hline & & $784 \mathrm{~kJ}$ & 604 & $861 \mathrm{~kJ}$ & 631 & $763 \mathrm{~kJ}$ & 586 & $747 \mathrm{~kJ}$ & 613 & $876 \mathrm{~kJ}$ & 773 & 584 kJ & 555 \\
\hline & Saturated fat $(g)$ & $2.9 \mathrm{~g}$ & 3.2 & $3.2 \mathrm{~g}$ & 3.5 & $2.8 \mathrm{~g}$ & 3.0 & $2.9 \mathrm{~g}$ & 3.2 & $3.5 \mathrm{~g}$ & 3.9 & $2 \cdot 3 \mathrm{mg}$ & $2 \cdot 9$ \\
\hline & $\mathrm{Na}(\mathrm{mg})$ & $217 \mathrm{mg}$ & 265 & $248 \mathrm{mg}$ & 283 & 228 mg & 263 & 195 mg & 250 & $237 \mathrm{mg}$ & 276 & $141 \mathrm{mg}$ & 216 \\
\hline & Total grams $(\mathrm{g})$ & $215 \mathrm{~g}$ & 179 & $228 \mathrm{~g}$ & 154 & $225 \mathrm{~g}$ & 139 & $211 \mathrm{~g}$ & 139 & $219 \mathrm{~g}$ & 155 & $174 \mathrm{~g}$ & 133 \\
\hline & Energy density (kJ/g) & $5.0 \mathrm{~kJ} / \mathrm{g}$ & 4.8 & $5.3 \mathrm{~kJ} / \mathrm{g}$ & $5 \cdot 0$ & $4.1 \mathrm{~kJ} / \mathrm{g}$ & 3.5 & $4.9 \mathrm{~kJ} / \mathrm{g}$ & 4.8 & $5.4 \mathrm{~kJ} / \mathrm{g}$ & $5 \cdot 0$ & $5 \cdot 2 \mathrm{~kJ} / \mathrm{g}$ & $6 \cdot 0$ \\
\hline & Fruit $(\mathrm{g})$ & $30 \mathrm{~g}$ & 0.5 & $29 \mathrm{~g}$ & 0.7 & $43 \mathrm{~g}$ & 2.5 & $33 \mathrm{~g}$ & 0.8 & $36 \mathrm{~g}$ & 2.9 & $29 \mathrm{~g}$ & 0.9 \\
\hline & Vegetables (g) & $12 \mathrm{~g}$ & 0.3 & $15 \mathrm{~g}$ & 0.4 & $13 \mathrm{~g}$ & $1 \cdot 1$ & $8 \mathrm{~g}$ & 0.3 & $9 \mathrm{~g}$ & 1.4 & $7 \mathrm{~g}$ & 0.4 \\
\hline
\end{tabular}

with when children were with parents, children consumed significantly more energy, $\mathrm{Na}$, added sugars, total grams, saturated fat and vegetables per eating occasion when accompanied by wider family. They also consumed higher energy dense meals. This equates to, on average, an additional $62 \mathrm{~kJ}, 19 \mathrm{mg}$ of $\mathrm{Na}, 0.6 \mathrm{~g}$ of added sugars, $0 \cdot 2 \mathrm{~g}$ of saturated fat and $3 \mathrm{~g}$ of vegetables per eating occasion. Furthermore, children consumed an additional $12 \mathrm{~g}$ of food and $0 \cdot 3$ kilojoules per gram per eating occasion when accompanied by wider family members compared with parents. No significant differences were found between the amount of fruit consumed when children were with their parents $v$. when they were with wider family members.

When children were accompanied by a formal childcare provider, they consumed significantly less added sugars $(-1.6 \mathrm{~g})$, significantly more fruit (12 g) and significantly less energy dense foods $(-0.86 \mathrm{~kJ} / \mathrm{g})$ per eating occasion than when they were with their parents. No significant differences were found between parents and formal childcare providers for the other dietary outcomes.

When no adults were specified, children ate significantly less energy $(-51 \mathrm{~kJ}), \mathrm{Na}(-25 \mathrm{mg})$ and vegetables $(-4 \mathrm{~g})$ and significantly more fruit $(4 \mathrm{~g})$ per eating occasion than when there were with their parents. They also consumed significantly lower energy-dense eating occasions $(-0.25 \mathrm{~kJ} / \mathrm{g})$.

When who the child was with was not recorded, children ate significantly less energy $(-227 \mathrm{~kJ}), \mathrm{Na}(-82 \mathrm{mg})$, added sugars $(-1.0 \mathrm{~g})$, saturated fat $(-0.7 \mathrm{~g})$ and vegetables $(-6 \mathrm{~g})$ than when accompanied by parents. They also consumed significantly less weight in grams $(-41 \mathrm{~g})$.

When children were accompanied by others, they ate significantly more energy $(66 \mathrm{~kJ})$, added sugars $(1.0 \mathrm{~g})$ and saturated fat $(0.4 \mathrm{~g})$ per eating occasion compared with when they were accompanied by their parents. When no adult was specified, children ate significantly less energy $(-51 \mathrm{~kJ})$ and $\mathrm{Na}(-25 \mathrm{mg})$ per eating occasion.

\section{Influence of household income on child nutritional intake}

Further analysis was conducted to explore the influence of household income on child intake. Children in families in the high-income category ( $>\$ 32500$ equivalised household income) consumed significantly less $\mathrm{Na}(-32 \mathrm{mg}, P=0 \cdot 001)$ and lower energy-dense meals $(-0.4 \mathrm{~kJ} / \mathrm{g}, P=0.014)$ than children in the low-income category $(£<17500)$. Children in the middle-income category ( $£ 17500-£ 32500)$ consumed less $\mathrm{Na}(-27 \mathrm{mg}, P=0 \cdot 006)$ and lower energy-dense meals $(-0.4 \mathrm{~kJ} / \mathrm{g}, P=0.015)$ compared with children in the low-income category $(£<17500)$. Very few significant interactions were found between income and accompanying people. Children from families in the high-income group (> $£ 32$ 500) consumed significantly higher energy-dense meals when accompanied by wider family members $(0.7 \mathrm{~kJ} / \mathrm{g}, P=0.024)$ or when no adults was specified $(0.6 \mathrm{~kJ} / \mathrm{g}, P=0.039)$ compared with children in the low-income group $(<£ 17500)$ when accompanied by parents. There were no other significant interactions between wider family members and income status for other nutritional elements.

Significant interactions were found between the household income status and when children were accompanied by formal childcare providers, when no adult was specified and when not recorded. When children from the high-income group were accompanied by formal childcare providers, they consumed significantly more $\mathrm{Na}(116 \mathrm{mg}, P=0.033)$ than children from families in the low-income group when accompanied by parents. Also, when children from the high-income group were with their formal childcare providers, they consumed significantly more vegetables ( $7 \mathrm{~g}, P=0.017$ ) than children from families in the low-income group when accompanied by parents. When no adults were specified, children from families in the high-income group consumed significantly fewer total grams per eating occasion $(-28, P=0.014)$ than children from families in the lowincome group when accompanied by parents. When who the child was with was not recorded, children from families in the high-income group consumed significantly less total grams $(-19 \mathrm{~g}, P=0.049)$ than children from families in the low-income group when accompanied by parents. When who the child was with was not recorded, children from families in the middleincome group consumed significantly more vegetables (14 g, $P<0 \cdot 001)$ than children from families in the low-income group when accompanied by parents. Full tables of results can be found in appendix 2 .

\section{Results of the sensitivity analysis}

The sensitivity analysis used assumptions based on the time items were consumed to control for meal type (i.e. breakfast, lunch, evening meal or snack). Across the nutritional elements, whether the results were significant or not did not change for most of the categories of accompanying people. However, 
Table 4. Results of the regression analyses of child nutritional intake when accompanied by different caregivers (Coefficient values and $95 \%$ confidence intervals)

\begin{tabular}{|c|c|c|c|c|c|c|c|c|c|c|c|c|c|c|c|c|c|c|c|c|c|c|c|c|}
\hline & \multicolumn{3}{|c|}{ Energy density $(\mathrm{kJ} / \mathrm{g})$} & \multicolumn{3}{|c|}{ Energy (kJ) } & \multicolumn{3}{|c|}{$\mathrm{Na}(\mathrm{mg})$} & \multicolumn{3}{|c|}{ Added sugars (g) } & \multicolumn{3}{|c|}{ Total grams (g) } & \multicolumn{3}{|c|}{ Saturated fat (g) } & \multicolumn{3}{|c|}{ Fruit (g) } & \multicolumn{3}{|c|}{ Vegetables $(\mathrm{g})$} \\
\hline & Coef. & $95 \% \mathrm{Cl}$ & $P$ value & Coef. & $95 \% \mathrm{Cl}$ & $P$ value & Coef. & $95 \% \mathrm{Cl}$ & $P$ value & Coef. & $95 \% \mathrm{Cl}$ & $P$ value & Coef. & $95 \% \mathrm{Cl}$ & $P$ value & Coef. & $95 \% \mathrm{Cl}$ & $P$ value & Coef. & $95 \% \mathrm{Cl}$ & $P$ value & Coef. & $95 \% \mathrm{Cl}$ & $P$ value \\
\hline Parents & & & & & & & & & & & & Reference & & & & & & & & & & & & \\
\hline Wider Family & 0.3 & $0.09,0.155$ & $0.007^{\star}$ & 62 & 27,97 & $P<0.001$ & 19 & 6,32 & $0.005^{*}$ & 0.6 & $0.1,1.1$ & $0.024^{*}$ & 12 & 3,21 & $0.007^{*}$ & 0.2 & $0.1,0.4$ & $0.006^{*}$ & -1 & $-3,3$ & 0.757 & 3 & 1,4 & $P<0.001$ \\
\hline $\begin{array}{l}\text { Formal } \\
\text { childcare } \\
\text { provider }\end{array}$ & -0.86 & $-1 \cdot 37,-0.34$ & $0.001^{*}$ & -1 & $-98,95$ & 0.982 & 26 & $-25,78$ & 0.319 & $-1 \cdot 6$ & $-2 \cdot 4,-0.8$ & $P<0.001$ & 19 & $-0.5,39$ & 0.056 & -0.1 & $-0.5,0.3$ & 0.593 & 12 & 3,21 & $0.01^{*}$ & -1 & $-5,2$ & 0.374 \\
\hline $\begin{array}{l}\text { No adults } \\
\text { specified }\end{array}$ & -0.25 & $-0.50,-0.01$ & $0.043^{*}$ & -51 & $-85,-17$ & $0.003^{\star}$ & -25 & $-39,-11$ & $P<0.001$ & -0.4 & $-0.9,0.1$ & 0.104 & -3 & $-12,6$ & 0.498 & -0.1 & $-0.3,0.1$ & 0.169 & 4 & 0,7 & $0.042^{*}$ & -4 & $-6,03$ & $P<0.001$ \\
\hline Other & 0.50 & $-0.03,1.01$ & 0.066 & 66 & 0,133 & $0.049^{*}$ & 13 & $-11,36$ & 0.286 & 1.0 & $0 \cdot 1,2 \cdot 0$ & $0.032^{*}$ & 0 & $-15,16$ & 0.989 & 0.4 & $0.1,0.7$ & $0.02^{\star}$ & 7 & $-1,14$ & 0.085 & -3 & $-7,1$ & 0.179 \\
\hline Not recorded & -0.15 & $-0 \cdot 30,-0 \cdot 27$ & 0.919 & -227 & $-261,-193$ & $P<0.001$ & -82 & $-94,-70$ & $P<0.001$ & -1.0 & $-1.5,-0.6$ & $P<0.001$ & -41 & $-48,-33$ & $P<0.001$ & -0.7 & $-1 \cdot 0,-0.6$ & $P<0.001$ & 1 & $-2,4$ & 0.639 & -6 & $-7,-5$ & $P<0.001$ \\
\hline
\end{tabular}

* Significant at $P<0.05$

Controlling for child BMI, child age, child sex, equivalised household income, child ethnicity. 
controlling for meal type led to some differences in the results of the regression analyses for dietary intake when accompanied by formal childcare providers and when no adult was specified. There was no longer a significant increase in children's consumption of fruit when accompanied by formal childcare providers compared with parents and unlike in the base case analysis, children consumed significantly more total grams (33 g) per eating occasion with formal childcare providers compared with parents. There was no longer a significant reduction in energy $(\mathrm{kJ})$ or increase in fruit $(\mathrm{g})$ intake when no adults were specified. Additionally, the significant difference observed for Na consumption or vegetable consumption when accompanied by wider family were no longer evident. Full tables of results can be found in appendix 3 .

\section{Discussion}

This study explored the dietary intake of children aged 2 to 4 years when accompanied by different adults, using data from the UK NDNS. The results demonstrate that preschool children consume larger portion sizes of meals, with a higher energy density, containing more vegetables, and higher in energy, salt, saturated fat and added sugar content when with wider family members compared to when with parents. However, parents and wider family members may provide similar amounts of fruit to preschool aged children as no differences in fruit intake were found when children were with parents $v$. wider family members. In contrast, preschoolers appear to be consuming more fruit when they are with their formal childcare providers, since fruit intake was higher when children were with their formal childcare providers compared with when they were with their parents. Formal childcare providers also appeared to be providing foods significantly lower in added sugars and energy density compared with parents.

While the differences in nutrient intakes are relatively small, this study focused on individual eating occasions, and considering that children of this age are recommended to consume three meals and two snacks per $\mathrm{d}^{(38)}$, these differences can add up. For instance, in the current study, the difference of 62 kilojoules per eating occasion found between parents and wider family could equate to an additional $310 \mathrm{~kJ} / \mathrm{d}$ or $2170 \mathrm{~kJ} /$ week. It was already known that children in the UK consume over double the recommended amount of added sugar per $\mathrm{d}^{(2)}$, but our study shows that this is even more likely when accompanied by wider family members $v$. by parents.

This study found that children were consuming significantly less energy and $\mathrm{Na}$ when no adult was specified. This includes meal occasions accompanied by friends and siblings. Similarly, it is also worth noting the significantly lower intakes found for most dietary outcomes when who the child was with was not recorded. It is unknown why this may be and indeed the results may reflect actual intake, but they may also reveal inaccuracies in the dietary assessment method. Underreporting is the most common misreporting error in dietary assessment ${ }^{(39)}$ and may explain the significantly lower intakes recorded. As participants forgot to record the 'who with' response, parents may have been distracted or busy when completing the diary, or it might indicate when they forgot to complete the diary prospectively and completed it at another time point. Likewise, when no adult was specified, children were accompanied by siblings or friends and may also have meant that respondents were less focused on completing the diary. Any of these factors could impact on the accuracy of the food diary entries and consequently the validity of these results ${ }^{(40)}$.

The results of this study suggest that children are consuming more fruit when with formal childcare providers compared with parents. This finding reflects the existing literature exploring childminders' food provision to preschoolers, whereby in the UK study of eight childminders, childminders relied heavily on fruit as a snack food item ${ }^{(14)}$. Children were also consuming significantly less added sugars and lower energy dense meals with formal childcare providers, which is in line with previous research demonstrating that childminders can successfully identify foods high in sugar and are confident in limiting unhealthy snacks and sugary drinks ${ }^{(41)}$. Due to the paucity of research carried out on food provision and eating behaviours in UK formal childcare settings, the current findings also conflict with a previous piece of research on food provision in formal childcare. Moore et al. reported that children were not frequently provided with fruit or vegetables with the main meal in formal childcare settings ${ }^{(12)}$. One explanation for this discrepancy is that the previous study was conducted prior to the introduction of the voluntary food and drink guidelines for Early Years Settings in England ${ }^{(42)}$, and that the current results reflect the changes made by nursery settings in light of this guidance.

Our findings on fruit and vegetable intake align with a previous study exploring fruit and vegetable consumption and the eating context using data from 2008 to 2010 of the $\mathrm{NDNS}^{(20)}$. For instance, similar to the significantly greater intake of vegetables when accompanied by wider family observed in our study, Mak et al. ${ }^{(20)}$ found that young children were more likely to consume vegetables when with adult relatives. Likewise Mak et al. found that young children were also more likely to consume fruit when they were with their formal childcare providers and when they were with friends ${ }^{(20)}$, reflecting the significantly greater intake of fruit that we found for children when with formal childcare providers and when no adult was specified, a category which included being with friends. However some of our results differ from this study; Mak et $a l^{(20)}$ found that young children were more likely to consume vegetables when with formal childcare providers compared with when they were with their parents alone, but we found no such differences in vegetable consumption. This difference may arise from the size of the study, for instance, our study combined data from three waves of the NDNS (2008-2011, 2012-2014 and 2014-2016) and used multiple imputation to account for missing data, resulting in over 30000 eating occasions. In contrast, Mak et al. conducted a complete case analysis on data from only 2 years of the NDNS dataset resulting in less than 5000 eating occasions for children aged 1.5 to 3 years ${ }^{(20)}$.

It is unknown who the wider family members were in our study; however, a survey of childcare in England found that informal childcare of children in the early years is mostly provided by grandparents ${ }^{(10)}$, and our results are consistent with the qualitative literature on grandparent's food provision to 
preschool aged children. For instance, parents frequently complain of grandparents providing their preschool aged grandchildren unhealthy options, high in fat and sugar ${ }^{(21,43-45)}$. Yet previously no study actually measured children's nutritional intake when in the care of grandparents, so it was unknown if these parental reports are accurate. Our findings seem to support this by demonstrating that preschool aged children consume greater amounts of saturated fat, sugar, salt and higher energy dense meals when accompanied by wider family members. Additionally, parents often complain that grandparents provide large portions sizes to their preschool aged children ${ }^{(21,45-47)}$. The provision of large portions prompts overconsumption ${ }^{(48)}$ and is a key driver of weight gain in young children ${ }^{(49,50)}$. Children in this study consumed significantly more total grams at a meal when with wider family members, suggesting that the portion sizes provided by family members could also be larger than those provided by parents.

One explanation for the increase in child consumption when accompanied by wider family members compared with parents is the effect of social facilitation. This is where the more people there are in a group eating, the more each individual will consume $^{(51)}$. The social facilitation effect on food consumption has been demonstrated widely in both adults and children and increases with the familiarity of the group ${ }^{(52,53)}$. When with wider family members, it is unknown how many people the children were accompanied by, and therefore the increase in consumption, of both energy $(\mathrm{kJ})$ and portion size $(\mathrm{g})$, may not be a direct result of the food provision practices of family members but influenced by the social situation. The social facilitation effect might also explain why children consumed more fruit when with formal childcare providers as it is likely that children would have been accompanied by other children in the childcare setting. Similarly, it could be an effect of peer-modelling, whereby fruit and vegetable consumption can be increased in children when they observe peers consuming such items ${ }^{(54)}$. However, contrary to these theories, no increase in consumption was found when no accompanying adult was specified, which included times when children were with friends and siblings. Highlighting the need for more detailed information on 'who with' and 'where' eating occasions occur.

An income gradient was seen in children's consumption, whereby children of higher-income families consumed less $\mathrm{Na}$ and lower energy-dense meals than children of lower-income families. This is in line with previous studies which have demonstrated how children from families of higher socio-economic status consume more healthful diets than children from families of lower socio-economic status ${ }^{(24,25)}$. However, when the interaction between the child's household income and who children were accompanied by was explored, the results were mixed. In line with the social gradient, children of higher-income families consumed significantly more vegetables when with their formal childcare providers compared with children of low-income families when accompanied by their parents. However, contrary to this gradient, we found that higher income was associated with the consumption of higher energy-dense meals when with wider family members, and more $\mathrm{Na}$ when with formal childcare providers compared with children of low-income families when accompanied by parents. Our measure of income was for the child's household, and we did not have the income details of the people the children were accompanied by. Considering an intergenerational transmission of socio-economic status has been consistently demonstrated ${ }^{(55)}$, it could be assumed that the wider family members and parents would be of a similar status, but the same cannot be said for formal childcare providers such as childminders. Future research should capture socioeconomic indices of the accompanying caregivers rather than just those of the child and further consider how socio-economic status influences the relationship between caregiver type and child intake.

To the authors knowledge, this is the first study to explore the association between young children's nutritional intake and caregiver type in the UK, providing evidence that further research is required in this area to effectively design targeted childhood obesity interventions. The NDNS provides highquality data on food and nutrition consumption and benefits from a large and representative sample. Consequently, the results provide a good indication of how children in the UK consume diets of a differing quality depending on who is looking after them. Nevertheless, several limitations are noteworthy. First, although the sample includes children from a range of deprivation levels and ethnicities, representative of the UK population ${ }^{(56,57)}$, being UK-specific, these findings may not generalise to outside of the UK. Nevertheless, similarities can be seen with studies in the USA where preschoolers' consume more fruit and vegetables in the childcare setting than at home ${ }^{(58,59)}$.

Second, this study considers individual eating occasions, rather than investigating dietary intake over a whole day. In the past, studies have found that young children self-regulate their food consumption to keep their daily energetic intake constant ${ }^{(60,61)}$, and therefore focusing on individual eating occasions may fail to account for any compensatory behaviour. However, more recent evidence suggests that there is large individual variability in self-regulation ${ }^{(62)}$ and that by the time children reach the preschool years this ability has mostly diminished as eating becomes more influenced by external cues $^{(63-65)}$. Importantly, looking at individual eating occasions may be the most appropriate way to explore the influence of different caregivers on young children's diets as children of this age may be fed by multiple caregivers across a 24-h period. Additionally, caregivers might influence children's consumption indirectly through the feeding practices or behaviours they use to guide children's eating behaviour, such as modelling healthy eating, restricting food and drink items or pressuring children to eat ${ }^{(65)}$. Although some feeding practices can lead to positive dietary outcomes, others can have unintended and negative effects $^{(66-68)}$. Our recent work suggests that there are no differences between parents and grandparents feeding practices when caring for preschool children ${ }^{(69)}$; however, differences in feeding practices between childcare staff and parents have been identified $^{(70)}$. Future work should aim to further explore how feeding practices of friends, other family members and childminders might also differ to parents and potentially impact on preschoolers' consumption.

Nutritional composition can also vary across meals and snacks ${ }^{(34)}$; however, data on the specific meal being 
consumed by children or whether foods were consumed as a snack were not explicitly available within the NDNS dataset. Although this was attempted in the sensitivity analysis using crude assumptions based on the times eating occasions occurred. Controlling for meal type resulted in some differences in the regression analysis for dietary intake when children were accompanied by formal childcare providers, and when no adult was specified, compared with the base case analysis. There was no longer a significant increase in fruit intake for formal childcare providers $v$. parents. However, it is likely that the change in fruit intake when accompanied by formal childcare providers is due to formal childcare providers offering a higher proportion of lunches and snacks compared with parents (data not shown). The sensitivity analysis shows that lunches contain significantly more fruit, and it is likely that the base case analysis is capturing this and assigning it to the formal caregivers category. The sensitivity analysis also demonstrates that children consumed approximately $33 \mathrm{~g}$ of more food overall per eating occasion with formal childcare providers compared with parents. However, rather than contradicting the findings of the base case analysis, these findings confirm the overall trend. Furthermore, there was no longer a significant reduction in energy consumed or increase in fruit intake when no adults were specified. The changes to these findings are likely also to be driven by the types of foods in specific meals or snacks consumed when no adults are present. Differences in $\mathrm{Na}$ and vegetable intake when accompanied by wider family were no longer statistically significant in the sensitivity analysis. In both cases, the magnitude of the coefficient has reduced; however, the direction did not change. It is worth noting that only a crude assumption of meal time was applied to the sensitivity analysis, and therefore these results should be interpreted with some caution since 'time of day' categories of eating occasions can eliminate foods consumed outside of traditional meal and snack patterns. Similarly, if a 'participant identified' approach to categorising meal times had been adopted, the data might be subject to bias from an individual's interpretation of what constitutes a meal or snack ${ }^{(72)}$. This highlights the need for clearly defined, objective and accurate information on meal times to be specified within the NDNS dataset. This would allow researchers to accurately define the food types that are consumed as part of specific meals and snacks.

A further limitation lies within the categories used to classify who the children were with when consuming food and drink items. Although the authors have tried to categorise the accompanying adults as best as possible, detailed information for the wider family category or the formal childcare category was not available. For instance, although there were separate categories for when children were with their parents, it was not possible to distinguish between different family members within the wider family category or different childcare types within the formal childcare category. Consequently, the results cannot provide more detailed accounts of who the children were with when consuming foods, for instance, an auntie $v$. a grandparent. Additionally, it is unknown how many people the children were accompanied by when eating and the dataset only contained information on who the children were with, not who specifically provided food to the children. There could have been occasions when parents provided food for their child to take to formal childcare settings.

For a lack of more robust evidence, this study indicates significant differences in young children's dietary intake depending on which caregivers they are with. It demonstrates the need for a more focused exploration of the diets of young children when cared for by people other than parents. This includes different family members such as grandparents, aunties or uncles as well as care providers such a childminders and nurseries. Further research is needed to explore these differences in more detail and ensure that studies are designed to encompass more than just a single food group to understand the overall influence these caregivers are having on preschoolers' diets. Adopting a measure of diet quality would also improve future studies, since these data would also allow for researchers to more easily identify those children at increased risk of not consuming optimal diets. These data are also useful for comparing dietary intake of specific groups, with different caregivers, to current dietary intake guidelines and recommendations, and for evaluating the effectiveness of interventions. This study also does not reveal anything about the frequency of food consumption when children are with different caregivers. Although caregivers are encouraged to provide some snacks to children of this age, the frequency in which young children consume snacks can have a significant effect on daily energy intake ${ }^{(73)}$. Consequently, future work should also explore any differences in the frequency of food provision between different caregivers.

Several implications for policy and practice have been highlighted in this study. The results suggest that other caregivers may be an important target to promote healthy eating in young children. To do so, it will be necessary to understand what type of strategy is most appropriate for reaching and engaging these caregivers. Although UK public health strategies, such as frontof-pack labelling, exist to reduce young children's fat, sugar and salt intake, many young children are consuming diets low in fruit and vegetables, high in energy, $\mathrm{Na}$ and $\operatorname{sugar}^{(2)}$, and large portion sizes of high energy-dense snack food items ${ }^{(74,75)}$. Current methods may not be reaching these care providers or they might not realise they need support in their provision. Non-parental caregivers may assume different feeding roles to that of parents and an awareness of this is needed to design effective strategies.

In conclusion, this study takes a novel approach to explore the influence of different caregivers on young children's diets. Using a large representative UK sample, we have demonstrated that preschool children consume meals/snacks higher in energy, saturated fat, sugar and salt, but they contain greater amounts of vegetables, with wider family members compared with when they are with their parents. Differences were also observed when preschool children were with formal childcare providers; more fruit and less added sugars were consumed by preschool children when with formal childcare providers compared with when they were with their parents. Even though parents may be the primary caregiver to young children, other caregivers can play a pivotal role in the dietary habits of young children. Nevertheless, further research should seek to explore these differences in more detail. 


\section{Acknowledgements}

This research was funded by the Wellcome Trust [108903/B/15/ $Z]$ and the University of Sheffield. For the purpose of Open Access, the author has applied a CC BY public copyright licence to any Author Accepted Manuscript version arising from this submission.

Conceptualisation: C. M., P. B. and S. J. C.; Methodology: C. M., P. B. and S. J. C.; Formal Analysis: C. M.; Writing-Original Draft Preparation; C. M.; Writing-Review and Editing: C. M., P. B and S. J. C.

There are no conflicts of interest.

\section{Supplementary material}

For supplementary material/s referred to in this article, please visit https://doi.org/10.1017/S0007114521004712

\section{References}

1. World Health Organization (2021) Obesity and Overweight. Key Facts. https://www.who.int/news-room/fact-sheets/ detail/obesity-and-overweight (accessed September 2021).

2. Public Health England (2016) National Diet and Nutrition Survey. https://www.gov.uk/government/collections/nation al-diet-and-nutrition-survey (accessed September 2020).

3. NHS Digital (2018) Health Survey for England, Fruit and Vegetable Consumption. http://healthsurvey.hscic.gov.uk/ data-visualisation/data-visualisation/explore-the-trends/fruitvegetables.aspx (accessed November 2021).

4. Golan M (2006) Parents as agents of change in childhood obesity - from research to practice. Int J Pediatr Obes 1, 66-76.

5. Peters J, Sinn N, Campbell K, et al. (2012) Parental influences on the diets of 2-5-year-old children: systematic review of interventions. Early Child Dev Care 182, 837-857.

6. Hooley M, Skouteris H, Boganin C, et al. (2012) Parental influence and the development of dental caries in children aged 0-6 years: a systematic review of the literature. J Dent $\mathbf{4 0}$, 873-885.

7. Skouteris H, McCabe M, Swinburn B, et al. (2011) Parental influence and obesity prevention in pre-schoolers: a systematic review of interventions. Obes Rev 12, 315-328.

8. Blaine RE, Kachurak A, Davison KK, et al. (2017) Food parenting and child snacking: a systematic review. Int $J$ Behav Nutr Phys Act 14, 1-23.

9. Office for National Statistics (2019) Families and the Labour Market, UK 2019. https://www.ons.gov.uk/employmentan dlabourmarket/peopleinwork/employmentandemployeetypes/ articles/familiesandthelabourmarketengland/2019\#employmentrates-for-parents-in-the-uk (accessed January 2020)

10. Department for Education (2018) Childcare and Early Years Survey of Parents in England, 2018. https://assets.publishing. service.gov.uk/government/uploads/system/uploads/attach ment_data/file/766498/Childcare_and_Early_Years_Survey_ of_Parents_in_England_2018.pdf (accessed February 2020).

11. Parker M, Lloyd-Williams F, Weston G, et al. (2011) Nursery nutrition in Liverpool: an exploration of practice and nutritional analysis of food provided. Public Health Nutr 14, 1867-1875.

12. Moore H, Nelson P, Marshall J, et al. (2005) Laying foundations for health: food provision for under $5 \mathrm{~s}$ in day care. Appetite $\mathbf{4 4}$, 207-213.
13. Neelon SEB, Burgoine T, Hesketh KR, et al. (2015) Nutrition practices of nurseries in England. Comparison with national guidelines. Appetite 85, 22-29.

14. Goldsborough N, Homer C, Atchinson R, et al. (2016) Healthy eating in the early years: a qualitative exploration of food provision in the childminder setting. Br Food J 118, 992-1002.

15. Pearce A, Li L, Abbas J, et al. (2010) Is childcare associated with the risk of overweight and obesity in the early years? Findings from the UK millennium cohort study. Int JObes 34, 1160-1168.

16. Costa S, Bann D, Benjamin-Neelon SE, et al. (2020) Associations of childcare type, age at start, and intensity with body mass index trajectories from 10 to 42 years of age in the 1970 British cohort study. Pediatr Obes 15, e12644.

17. Costa S, Adams J, Gonzalez-Nahm S, et al. (2017) Childcare in infancy and later obesity: a narrative review of longitudinal studies. Curr Pediatr Rep 5, 118-131.

18. MRC Elsie Widdowson Laboratory \& NatCen Social Research (2018) National Diet and Nutrition Survey Years 1-8, 2008/ 09-2015/16, 12th ed. Colchester, UK: UK Data Service.

19. Burrows TL, Martin RJ \& Collins CE (2010) A systematic review of the validity of dietary assessment methods in children when compared with the method of doubly labeled water. J Am Diet Assoc 110, 1501-1510.

20. Mak TN, Prynne CJ, Cole D, et al. (2012) Assessing eating context and fruit and vegetable consumption in children: new methods using food diaries in the UK national diet and nutrition survey rolling programme. Int J Behav Nutr Phys Act 9, 126.

21. Marr C, Reale S, Breeze P, et al. (2020) Grandparental dietary provision, feeding practices and feeding styles when caring for preschool-aged grandchildren: a systematic mixed methods review. Obes Rev 22, e13157.

22. Northstone K \& Emmett PM (2010) Dietary patterns of men in ALSPAC: associations with socio-demographic and lifestyle characteristics, nutrient intake and comparison with women's dietary patterns. Eur J Clin Nutr 64, 978-986.

23. Darmon N \& Drewnowski A (2015) Contribution of food prices and diet cost to socioeconomic disparities in diet quality and health: a systematic review and analysis. Nutr Rev 73, 643-660.

24. Nelson M (2020) Childhood nutrition and poverty. Proc Nutr Soc 59, 307-315.

25. Craig LCA, McNeill G, MacDiarmid JI, et al. (2010) Dietary patterns of school-age children in Scotland: association with socio-economic indicators, physical activity and obesity. $\mathrm{Br} \mathrm{J}$ Nutr 103, 319-334.

26. World Health Organization (2016) The WHO Child Growth Standards. http://www.who.int/childgrowth/en/ (accessed September 2020)

27. Wright CM, Booth IW, Buckler JMH, et al. (2002) Growth reference charts for use in the United Kingdom. Arch Dis Child 86, $11-14$.

28. Galobardes B, Shaw M, Lawlor DA, et al. (2006) Indicators of socioeconomic position (part 1). J Epidemiol Community Health 60, 7-12.

29. Orrell-Valente JK, Hill LG, Brechwald WA, et al. (2007) "Just three more bites": an observational analysis of parents' socialization of children's eating at mealtime. Appetite 48, 37-45.

30. Nguyen CD, Carlin JB \& Lee KJ (2017) Model checking in multiple imputation: an overview and case study. Emerg Themes Epidemiol 14, 8.

31. White IR, Royston P \& Wood AM (2011) Multiple imputation using chained equations: issues and guidance for practice. Stat Med 30, 377-399.

32. Rubin DB (1987) Multiple Imputation for Nonresponse in Surveys. Hoboken, NJ: John Wiley \& Sons, Inc. 
33. Summerbell C, Moody RC, Shanks K, et al. (1995) Sources of energy from meals versus snacks in 220 people in four age groups. The ToyBox-study View project NIHR systematic reviews examining the effectiveness of interventions to reduce socioeconomic inequalities in child and adult obesity. Eur J Clin Nutr 49, 33-41.

34. Bellisle F, Dalix AM, Mennen L, et al. (2003) Contribution of snacks and meals in the diet of French adults: a diet-diary study. Physiol Behav 79, 183-189.

35. Kant AK \& Graubard BI (2015) 40-Year trends in meal and snack eating behaviors of American adults. J Acad Nutr Diet 115, 50-63.

36. O'Connor L, Brage S, Griffin SJ, et al. (2015) The cross-sectional association between snacking behaviour and measures of adiposity: the Fenland study, UK. Br J Nutr 114, 1286-1293.

37. Gaal S, Kerr MA, Ward M, et al. (2018) Breakfast consumption in the UK: patterns, nutrient intake and diet quality. A study from the international breakfast research initiative group. Nutrients 10, 999.

38. Public Health England (2019) Change4Life Nutrition Campaign. https://campaignresources.phe.gov.uk/resources/campaigns/ 84-2019-change4life-nutrition-campaign (accessed February 2020).

39. Forrestal SG (2011) Energy intake misreporting among children and adolescents: a literature review. Matern Child Nutr 7, $112-127$.

40. Ortega RM, Pérez-Rodrigo C \& López-Sobaler AM (2015) Dietary assessment methods: dietary records. Nutr Hosp $\mathbf{3 1}$, $38-45$

41. Wallace R \& Mills B (2019) A study of the food environment at Australian family day care. Nutr $\mathbf{1 1}, 10$.

42. Children's Food Trust (2012) Voluntary Food and Drink Guidelines for Early Years Settings in England-A Practical Guide. https://www.activematters.org/wp-content/uploads/ pdfs/CFT\%20Early\%20Years\%20Guide_Interactive_Sept $\% 2012$. pdf (accessed February 2020).

43. Eli K, Howell K, Fisher PA, et al. (2016) A question of balance: explaining differences between parental and grandparental perspectives on preschoolers' feeding and physical activity. Soc Sci Med 154, 28-35.

44. Mena NZ, Gorman K, Dickin K, et al. (2015) Contextual and cultural influences on parental feeding practices and involvement in child care centers among Hispanic parents. Child Obes 11, 347-354.

45. Dwyer J, Needham L, Simpson JR, et al. (2008) Parents report intrapersonal, interpersonal, and environmental barriers to supporting healthy eating and physical activity among their preschoolers. Appl Physiol Nutr Metab 33, 338-346.

46. Lindsay AC, Sussner KM, Greaney ML, et al. (2009) Influence of social context on eating, physical activity, and sedentary behaviors of Latina mothers and their preschool-age children. Health Educ Behav 36, 81-96.

47. Jiang J, Rosenqvist U, Wang $\mathrm{H}$, et al. (2007) Influence of grandparents on eating behaviors of young children in Chinese three-generation families. Appetite 48, 377-383.

48. Hetherington MM \& Blundell-Birtill P (2018) The portion size effect and overconsumption - towards downsizing solutions for children and adolescents. Nutr Bull 43, 61-68.

49. Syrad H, Llewellyn CH, Johnson L, et al. (2016) Meal size is a critical driver of weight gain in early childhood. Sci Rep $\mathbf{6}$, 28368.

50. McConahy KL, Smiciklas-Wright H, Birch LL, et al. (2002) Food portions are positively related to energy intake and body weight in early childhood. J Pediatr 140, 340-347.
51. De Castro JM (1997) Socio-cultural determinants of meal size and frequency. Br J Nutr 77, Suppl. 1, S39-S55.

52. Herman CP (2015) The social facilitation of eating. A review. Appetite 86, 61-73.

53. Ruddock HK, Brunstrom JM, Vartanian LR, et al. (2019) A systematic review and meta-analysis of the social facilitation of eating. Am J Clin Nutr 110, 842-861.

54. Lowe CF, Horne PJ, Tapper K, et al. (2004) Effects of a peer modelling and rewards-based intervention to increase fruit and vegetable consumption in children. Eur J Clin Nutr 58, 510-522.

55. Carvalho L (2012) Childhood circumstances and the intergenerational transmission of socioeconomic status. Demography 49, 913-938.

56. Department for Work and Pensions (2020) Households Below Average Income: An Analysis of UK Income Distributions: 1994/95-2018/19. https://assets.publishing.service.gov. uk/government/uploads/system/uploads/attachment_data/ file/875261/households-below-average-income-1994-19952018-2019.pdf (accessed December 2020).

57. Office for National Statistics (2018) UK Population by Ethnicity. https://www.ethnicity-facts-figures.service.gov.uk/ uk-population-by-ethnicity/national-and-regional-populations/ population-of-england-and-wales/latest\#by-ethnicity (accessed December 2020).

58. Robson SM, Khoury JC, Kalkwarf HJ, et al. (2015) Dietary intake of children attending full-time child care: what are they eating away from the child-care center? J Acad Nutr Diet $\mathbf{1 1 5}$, $1472-1478$.

59. Sisson SB, Kiger AC, Anundson KC, et al. (2017) Differences in preschool-age children's dietary intake between meals consumed at childcare and at home. Prev Med Rep 6, 33.

60. Birch LL, Johnson SL, Andresen G, et al. (1991) The variability of young children's energy intake. $N$ Engl J Med 324, 232-235.

61. Birch LL \& Deysher M (1986) Caloric compensation and sensory specific satiety: evidence for self regulation of food intake by young children. Appetite 7, 323-331.

62. Johnson SL (2000) Improving preschoolers' self-regulation of energy intake. Pediatrics 106, 1429-1435.

63. Fox MK, Devaney B, Reidy K, et al. (2006) Relationship between portion size and energy intake among infants and toddlers: evidence of self-regulation. J Am Diet Assoc 106, S77-S83.

64. Birch LL \& Davison KK (2001) Family environmental factors influencing the developing behavioral controls of food intake and childhood overweight. Pediatr Clin North Am 48, 893-907.

65. Rolls BJ, Engell D \& Birch LL (2000) Serving portion size influences 5-year-old but not 3-year-old children's food intakes. J Am Diet Assoc 100, 232-234.

66. Shloim N, Edelson LR, Martin N, et al. (2015) Parenting styles, feeding styles, feeding practices, and weight status in 4-12 year-old children: a systematic review of the literature. Front Psychol 6, 1849.

67. Ventura AK \& Birch LL (2008) Does parenting affect children's eating and weight status? Int J Behav Nutr Phys Act $\mathbf{5}, 15$.

68. Galloway AT, Fiorito L, Lee Y, et al. (2005) Parental pressure, dietary patterns, and weight status among girls who are "picky eaters." J Am Diet Assoc 105, 541-548.

69. Blissett J (2011) Relationships between parenting style, feeding style and feeding practices and fruit and vegetable consumption in early childhood. Appetite 57, 826-831. 
70. Marr C, Breeze P \& Caton SJ (2022) A comparison between parent and grandparent dietary provision, feeding styles and feeding practices when caring for preschool-aged children. Appetite, 168, 105777.

71. Gubbels JS, Stessen K, van de Kolk I, et al. (2018) Energy balance-related parenting and child-care practices: the importance of meso-system consistency. PLOS ONE 13, e0203689.

72. Leech RM, Worsley A, Timperio A, et al. (2015) Understanding meal patterns: definitions, methodology and impact on nutrient intake and diet quality. Nutr Res Rev 28, 1-21.
73. Xue H, Maguire RL, Liu J, et al. (2019) Snacking frequency and dietary intake in toddlers and preschool children. Appetite 142, 104369.

74. Infant \& Toddler Forum (2016) Healthy Eating For Toddlers Portion Size Survey. https://infantandtoddlerforum.org/todd lers-to-preschool/portion-sizes-for-toddlers/portion-sizessurvey/ (accessed June 2021).

75. Deming DM, Reidy KC, Fox MK, et al. (2017) Cross-sectional analysis of eating patterns and snacking in the US feeding infants and toddlers study 2008. Public Health Nutr 20, 1584-1592. 